\title{
School Truancy: Poor School Attenders' Perceptions of the Impact Regarding Dysfunctional Teacher-Learner Relationships on Truant Behaviour
}

\author{
Dr Maynard van Breda \\ College of Education, University of South Africa, South Africa \\ Email: vbredmj@unisa.ac.za
}

Doi:10.5901/mjss.2014.v5n23p1056

\begin{abstract}
The aim of this paper was to explore truants' perceptions of the impact of teacher's behaviour and attitudes on their school attendance. An in-depth literature study of the latest research on truancy uncovered that past truancy research focussed predominantly on the influence of home and community related influences in causing school truant behaviour. Three hundred eighth grade learners in the Metro East Education District (MEED) in the Western Cape, South Africa, participated in a survey measuring learners' perceptions of the effects teacher-learner relationship on school and lesson attendance. The research findings suggest that respondents perceive unfavourable school experiences including being rejected, discriminated against by teachers and subjection to undue and humiliating punitive measures as significant grounds for their deliberate absence from lessons and ultimately dropping out of school. In presenting the research findings, it is argued that teachers often overlook the effects their class room conduct and attitudes may have on learners' sense of belonging in school, learner school attendance and how learners view them. Therefore, it is strongly recommended that education authorities take account of the research findings of dysfunctional learner-teacher relationships in combatting school truancy.
\end{abstract}

Keywords: non-attendance; truancy; school; absenteeism; learner-teacher relationships.

\section{Introduction}

With the current emphasis on the dire need to offer quality education, greater demands are increasingly placed on schools to create learning environments in which learners not only feel safe, but also experience a genuine sense of belonging (Sheppard, 2009). This is particularly required in developing countries like South Africa where government policies are incrementally aiming at implementing inclusive approaches to teaching and learning. To this end, one of the most significant responsibilities teachers have is to balance the needs of the many with the needs of the few in their class rooms. It seems that when learners' safety is compromised and they do not experience a sense of acceptance and belonging at school, they tend to seek other environments in which these needs are acknowledged and satisfied. This often results in absenteeism, truancy and various other forms of disciplinary challenges that learners present with (McCray, 2006). Truancy in particular, is commonly considered one of the first signs which may be indicative that a learner is not only likely to experience challenges, but it may also increase the chances of dropping out of the school system. In many instances this form of learner response can be ascribed to the fact that chronically truant learners invariably experience great difficulty in catching up with academic work and eventually become totally disengaged from school (Fallis \& Opotow, 2003).

Nearly on a daily basis, hundreds of thousands of learners are absent from schools of whom many fail to turn up without an excuse and are therefore deemed truant. In the United States of America the issue of truancy has been identified as one of the top 10 major challenges facing the nation's education system as cited by De Kalb in (Kim and Page, 2011). Although national data on truancy rates in most countries are not readily available (partly because no uniform definition of truancy exists) many large schools across the world report staggering rates of truancy and chronic absenteeism. In view of this, a critical issue when examining truancy is to understand precisely what the concept means and implies. In Reid's view (2010), there exist a variety of types of school truancy and absenteeism and as such, the concept could have different meanings for different people. Truancy may refer to skipping of specific lessons, post registration absence, parentally condoned absence, psychological absence, school refusal as well as school phobia. In further elaborating on the definitional issue of truancy Reid (2010) postulates that for some educational practitioners, specific lesson absence, post registration absence and particularly parentally condoned absence, do not constitute truancy. For other practitioners they are, and are often retitled specific lesson truancy, post registration truancy and 
parentally condoned truancy. Therefore, on one level, being absent without a valid reason is equated with truancy, while on another level having good reason to be absent like for example in the case of a parentally condoned absentee means per definition that this form of behaviour is not truancy. Nevertheless, for the purpose of this paper, the term truancy will simply be referred to as any form of excessive unauthorised absence from school or certain lessons for no legitimate reason.

There seems to be an increasing belief and a growing recognition that poor school attendance and truancy not only has substantial cost implication for the individual learner, but for the wider society as well. On the individual level, persistent truant behaviour and school absenteeism are likely to lead to early school leaving coupled with a strong likelihood of economic disadvantage later in life. On a social level, on-going truant behaviour and absence from school has been found to be related to substance abuse, gang activity and involvement in criminal activity such as burglary, motor theft and vandalism. Much of the work in the area of developmental path ways to delinquency shows that the aforementioned behavioural problems, if prevalent in adulthood, are followed by progressively more serious behavioural and adjustment challenges, including an increased propensity for violent behaviour (Darmody, Smyth and McCoy, 2008). Moreover, adults who have frequently truanted as teenagers are said to be more likely than those who have not, to have poorer health and mental health, occupy low paying jobs, have an increased chance of living in poverty, are more likely to rely on welfare support, have children who exhibit difficult behaviours and present with an increased likelihood of incarceration (Kim and Page, 2013).

Significant attention has been paid to the study of the causes and correlates of truant behaviour among school learners world-wide, resulting in a massive body of research linking numerous risk factors to truancy (Donoghue, 2011; Ovink, 2011; Reid, 2010; Darmody, Smyth \& McCoy, 2008; Davies, \& Lee, 2006; Lindstadt, 2005). Interestingly, emerging from the strong corpus of literature on school absence and truancy, it does appear that the circumstances and causal factors leading to this behaviour have changed and become incrementally complex over the past two to three decade (Maynard, Salas-Wright, Vaughan and Peters, 2012; Reid, 2010). Growing consensus exists whereby factors and circumstances which lead to learners missing school seem to depend on the age and personal circumstances of individual learners. Based on the outcome of an American multisite reduction program which aimed at combatting truancy in seven school sites located throughout the United States including California, Hawaii, New York and Texas amongst other, the reasons for truancy fall into three broad categories which include family, economics and learner (Hendricks, Sale, Evans, Mckinley and Cater, 2010). Other studies have found risks factors at the individual, family and community levels to be narrowly linked to truancy. Lindstadt (2005) cited that the phenomenon of truancy (i.e., unexcused absence from school) is associated with a host of interconnected and overlapping negative individual, family, social and community risk factors. Since the exact nature and magnitude of truanting often vary, it is important to note that truancy may stem from multiple, often interrelated factors, resulting in learners skipping school or certain lessons without any valid excuse do not constitute a homogenous group. To combat truancy and increase learner school attendance, researchers, practitioners and schools have developed various strategies targeting a series of risk factors associated with truancy, resulting in diverse interventions and policies being implemented in various settings (Maynard, McCrea, Pigott and Kelly, 2013).

Moreover, recent decades saw school truancy becoming an area of particular policy interests resulting in the proliferation of new legal and regulatory initiatives to address this issue among learners. A drastic rise in truancy cases in countries like England and Wales coupled with a link between truancy and various forms of criminal behaviour lead to reforms to address unauthorised school absenteeism featuring prominently in the Labour Government's evolving social policy agenda. However, despite the frenetic creation and extension of legal tools and legal powers and a programme of reforms costing tax payers in excess of $£ 1 b n$, aimed specifically at combatting truant behaviour, school absenteeism and the rate of truancy for 2010 in England reached their highest level since 1997. It is estimated that around 2010, a total of approximately 68,000 learners of which the majority attended secondary schools were either absent or skipped classes on a regular basis in schools across England (Donoghue, 2011).

However, insights on the role of teacher attitudes in causing learners to become disaffected with school generally seem to be small-scale. In addition to this is the complexity in deducing the extent to which the interaction between learner characteristics, institutional and academic factors can be associated with truancy. Against this backdrop, this paper primarily aims to address truants' perceptions reagarding the influences of teacher-learner relations which may shape patterns of truant behaviour in South African schools, a country in which generally speaking, limited research has been conducted on truancy and school absence. The following section of the paper locates the research within the context of previous international and local research on truancy with general a reference to truancy as an important component of school absence and with specific focus on institutional or school related circumstances that can be associated with this type of learner behaviour. 


\section{Previous Truancy Research}

The body of knowledge on learner absenteeism and truant behaviour suggests that this may be one of the most challenging issues facing schools today according to Epstein and Sheldon, as cited in McCray (2006). It is widely believed that truancy often indicates larger issues in the life of a child for whom the world around him or her is often perceived as an unstable and confusing place (McCray, 2006). Gullat and Lemoine (1997) identified specific social causes of school truancy, including break up of traditional family structure, working mothers and growing sizes of communities. Similarly, Rorhman, as cited in Gallat and Lemoine (1997), suggested that truancy can be traced to lack of community support, chaotic family life as well as personal, academic and social deficits.

In their study of school absenteeism and truancy, Kinder, Harland, Wilken and Wakefield as cited in (Reid 2010) reported on their findings with 160 grade 7 learners that the main causes of truancy and disruptive behaviour include the influence of friends and peers, family aspects (parents negative attitudes towards education, domestic problems) and learner on learner bullying. In a different study, the same researchers found that the prime causes were individual, family and community factors. Individual aspects included: lack of self-esteem, social skills and confidence, poor peer relation, lack of academic ability, special needs, and lack of concentration as well as self-management skills. Family factors included: parentally condoned absence, not valuing education, domestic issues, inconsistent or inadequate parenting and economic deprivation. Community factors revolved around socio-economic factors, location, local attitudes and lack of community self-esteem.

According to the Office of Juvenile Justice and Delinquency Prevention (OJJDP), truancy is a serious concern that affects most school districts across the United States (Henry, 2007). Based on the research findings of Henry's study, this behaviour appears to be a common phenomenon among adolescence and can have deleterious effects not only for their current school career, but later in life as well. Furthermore, among the most salient predictors of recent truancy which featured significantly in this study, were parental educations, having large amounts of unsupervised time after school, school disengagement variables (e.g. poor grades and low educational aspirations) and drug use.

A truancy study conducted by Desforges and Abouchaar as cited in Sheppard (2009) which aimed to investigate learners' perceptions of specific parental involvement behaviour that might influence their school attendance and participation in schoolwork concluded that poor school attenders view their parents as more inconsistent in their responses to their requests to miss school. Furthermore, it also emerged from this study that more parentally-approved absences occurred among truants who perceived their parents to be less interested in their school work. In view of this, it was hypothesised that poorer attenders would show less confidence in their academic performance and perceive their parents as being less involved in their education (Sheppard, 2007).

Investigating the link between being bullied and truancy (Donoghue, 2011), several important and timely contributions are made by this author to the literature of the effects bullying and truancy and other disciplinary problems in school. Based on the results of this study, it is postulated that falling victim to bullying at school is significantly associated with higher levels of most - but not all - measures of school truancy and disciplinary challenges. The findings of this research further suggested that apart from translating into serious academic costs for the victims of bullying, their resultant truant behaviour as well as other disciplinary problems at school, invariably contribute to enormous missed opportunities to learn and engage with classmates and teachers in a meaningful way. Moreover, poor academic performance due to poor attendance and truancy, missed or late assignments may be compounded by the effects of any disciplinary responses to truancy that may be imposed by the school such as in-school suspension or detention (Donoghue, 2011). The significantly high levels of truancy and disciplinary challenges victims in this study presented with are also of concern given the difficulties that such behaviour poses to one's chances for school success and its association with getting into trouble as an adult.

According to Ovink (2011), truancy and school disengagement, which correlated highly with increased rates of poverty, early parenting, unemployment and a host of other personal and social ills in societies, invariably result in a significant loss of state funding for schools. This is notably the case where a large percentage of school resources are tied to Average Daily Attendance (ADA) numbers. Consequently high rates of school truancy is said to lead to an additional source of loss for communities in already underfunded public school districts (Ovink, 2011). This author further cited that the negative effects that stem from school truancy necessitate a thorough understanding of the experience of truancy, including its causes and consequences, how truancy is perceived and institutional responses that it illicit. An important aspect about truancy for Ovink (2011) is that understanding institutional responses, in other words how schools deal with truancy, can in fact help schools evaluate whether their efforts in combatting truant behaviour are achieving the desired outcomes.

Although truancy is incrementally developing into a serious problem in South African schools, only limited attempts 
have been made to thoroughly research this alarming issue. Dr Catherine Ward (2012), a senior lecturer in the depart of psychology at the University of Cape Town in South Africa, proposed that school truancy could act as an early warning sign helping authorities to identify children at risk of becoming homeless. Research on homeless people conducted by Ward, suggested that children who are thinking of going onto the streets often 'practice' by spending a day or so at a time on the streets and then going home at night. Upon interviewing learners found wondering on streets during school time, Ward (2012) found that truancy could be directly linked to poverty, as it emerged that children initially play truant because they feel they don't fit in at school. This may be due to the parents' inability to afford school fees or uniforms or other items that help children feel included in school. Hereby it is suggested that truancy can thus be considered a symptom of poverty.

In spite of the fact that existing research contributes to a large degree to our overall understanding of truancy as a social phenomenon, most studies consulted in the literature review failed to explore truancy as a school and curriculum related issue. I argue that a comprehensive analysis of the "problem of truancy" involves more than merely research only on home, community and individual causes of truant behaviour and its consequences. What we can learn about the meaning and effects of truancy therefore comes not just from families, communities and individual learners, but is also communicated by the methods of responses adopted by schools and education districts in dealing with this behaviour. The need to examine and critique school related circumstances impact on truancy has led me to include a section which measured truants' perceptions of their teachers' influence in causing and sustaining truancy as part of a larger doctoral study on truancy among early adolescent learners.

\section{Bio-Ecological Systems Theory}

A good deal of the research on school truancy has been largely a-theoretical and not clearly linked to understanding the role of school environmental factors in causing learners to stay absent from school or skip certain classes. Therefore, the author conceptualised this study within the context of Urie Bronfenbrenner's most recent Bio-Ecological System's theory in terms of which the psychosocial life world of a child comprises a multi-layered set of nested and interrelated ecological systems. These structures include, but extend beyond home, school and neighbourhood in which children spend their everyday lives and influence their development and adjustment (Berk, 2003). Based on the bio-ecological systems theory, the interrelations among the following systems can affect children's developmental outcomes: micro - immediate settings or environments including family, friends and school; meso - link between 2 or more microsystems, such as the home and school; exo - settings not directly affecting the individual but that influence the microsystems such as parent's work place or extended family; macro - broader society and culture that encompasses the other systems; and chrono consistency or change over the life course (Berk, 2003). Following a thorough analysis of the theory concerned, it emerged that child development and adjustment are neither controlled by environmental circumstances nor driven by inner dispositions only. Instead, it appears that children are both products and producers of their environments, within the network of the interdependent systems as described above. According to Brofenbrenner, it is the ideal situation if all systems are in harmony and prove to be supportive of an individual person, particularly in the case of a developing child who attends school (Berk, 2003). Following on the afore-mentioned, the author thus contends that Bronfenbrenner's ecological systems theory is not only an appropriate theoretical framework for the overall understanding of the nature and intensity of learner truant behaviour. However, it also seems to be of great value in promoting positive teacher-learner relationships and in fostering meaningful home-school cooperation.

\section{Research Methodology}

\subsection{Research approach and design}

This study employed a mixed method research methodology and was guided by a phenomenological descriptive design. A phenomenological study aims to understand specific people's perceptions and perspectives of a phenomenon as in this case - truants' perceptions of school based factors that contribute to their skipping of certain classes and unauthorised absence and to relate the findings to an existing body of knowledge. Therefore, the combination of literature reviews with the empirical study was embarked upon.

\subsection{Selection of participants}

A questionnaire was applied to 300 grade 8 learners at 6 high schools in MEED in the Western Cape, South Africa. This 
sample group of whom everyone remained anonymous comprised both genders and were randomly selected by their respective schools. The primary aim of the questionnaire was to ascertain who the typical truants and the so-called non truants in the sample were, while the secondary objective was to purposively select 2 suitable candidates to participate in in-depth case studies which followed. A comparative study of the psychosocial life worlds of these two learners was conducted. Certain aspects of the truant learner's perception of teacher related factors linked to truancy have been included in the discussion section of this paper. Purposeful selection is crucial in a phenomenological study in order to get 'rich information' to describe the phenomenon in this case being truants' views regarding school related factors and circumstances in causing them to skip school and certain classes deliberately (de Vos et al. 2005).

\subsection{Measuring instruments}

Following a thorough literature review and a focus group interview conducted with 6 learners who were confirmed by their schools as regular absentees and skipping classes, a questionnaire was designed. This survey was conducted aimed at ascertaining the respondents' perceptions and general feeling about school based circumstances that they associate with truancy. The questionnaire was administered qualitatively and quantitatively and it contained an open-ended question as well as closed items. A Likert scale response format was developed for the interpretation of the questionnaire. The reliability of the questionnaire was between 0,93 and 0,97 which may be considered reasonably well.

\subsection{Data collection and analysis}

The research was conducted with a specific aim in mind, namely to determine truants' perceptions of the contributing role that school related factors, with particular reference, the influence of teachers, to play in their truant behaviour. The survey was conducted simultaneously at the 6 participating schools in MEED. The data of the survey was analysed by means of appropriate statistical techniques including frequencies, percentages, analysis of variance (ANOVA) and chisquare analysis.

From the population sample that completed the questionnaire, 2 respondents were purposively selected to participate in in-depth case studies. Based on an analysis of the responses of these 2 respondents, one of them emerged as a typical truant, while the other surfaced as a typical non-truant. The aim of the case studies was to explore the possibility of any conflicting perceptions and feelings the case respondents may have with regard to school based influences in bringing about truant behaviour in learners.

\section{Results}

\subsection{Survey}

Table 1: Truants perceptions of how teachers' attitudes and influences towards them may lead to truant behaviour and school absenteeism:

\begin{tabular}{|c|c|c|c|c|}
\hline \multicolumn{2}{|c|}{ Items } & \multirow{2}{*}{\begin{tabular}{|c|}
$\begin{array}{c}\text { Strongly agree/ } \\
\text { agree }\end{array}$ \\
33.7
\end{tabular}} & \multirow{2}{*}{$\begin{array}{c}\text { Uncertain } \\
2.0\end{array}$} & \multirow{2}{*}{$\begin{array}{c}\text { Strongly disagree/ } \\
\text { disagree }\end{array}$} \\
\hline 1. & My teachers always give me attention at school. & & & \\
\hline 2. & My teachers treat me with respect. & 32.0 & 9.3 & 58.7 \\
\hline 3. & Teachers always value and respect my contributions. & 27.0 & 24.7 & 47.7 \\
\hline 4. & My teachers encourage me to attend school regularly. & 33.7 & 5.7 & 60.7 \\
\hline 5. & My teachers always try to make lessons interesting and meaningful. & 33.3 & 5.3 & 62.3 \\
\hline 6. & I know most of my teachers have my interests at heart. & 31.0 & 14.3 & 54.3 \\
\hline 7. & I feel very comfortable to discuss anything with my teachers. & 32.7 & 6.0 & 61.3 \\
\hline 8. & $\begin{array}{l}\text { My teachers do not say any negative or bad things about my work in front } \\
\text { of other learners. }\end{array}$ & 27.0 & 32.7 & 50.3 \\
\hline 9. & My teachers do not really make unreasonable demands on me. & 33.7 & 3.0 & 63.3 \\
\hline 10. & I will take any of my teachers as my role model. & 33.3 & 8.7 & 58.0 \\
\hline
\end{tabular}

The results in Table 1 clearly indicate truants' views on the negative impact of their school experiences as it consistently reflect how unfavourably they perceive their teachers influence in their school lives. 


\subsection{Truant learner: Gary (not his real name)}

Comparatively speaking, the outcome of the two case studies demonstrated stark differences in their perceptions of school experiences between the respondent who was identified as a typical truant and the other a typical non-truant. The typical truant named Gary, not dressed in full school uniform wearing a small earing shared his negative feelings and impressions about school in general and of some of his teachers very freely. According to Gary, his teachers only communicated with him when they yell at him for skipping some of his classes. Furthermore, Gary considered them (his teachers) as being extremely unconcerned, unfair and uncaring about him.

His response to this type of treatment was as follows:

"It makes me feel as if I don't belong in class. Even the other children in class who are favoured by teachers don't take much notice of a person. That is why I always feel lonely and very one-sided at school ... there are children who feel like me, because we always talk about the way certain teachers treat us and how full of nonsense they are."

When invited to elaborate further on the issue of favouritism in class, Gary had the following to say:

"I know quite a few teachers who make it very obvious that they only take note of clever children in class ... you know ... the ones that come from nice areas. They always speak nicely to them and never shout at them like they scold and shout at some of us who are struggling with our school work and don't live in posh areas. Maybe they think that if you live in a poor area then you don't belong in their school and you are too backward and dumb to do the work they give you".

Gary had the following to say upon a request to explain who he feels about teacher favouritism:

"It is not my fault that I live in a poor area ... I mean can I help where I live? I feel it is very unfair of teachers not to show interest in children who are less privileged and pick on a person every time for stupid things. What I can't take is when a teacher insults me in front of other children. And many times I just get so mad at everything and everyone at school that I just decide to go to the fence at the back of the school because I know there is a whole in ... and then I just escape through it and run away".

Asked about receiving corporal punishment, Gary expressed him as follows:

"They just want to hit a person, even if you did nothing wrong. Once I came late for one teacher's class because I was struggling to get done with a geography test in the previous period and still had to walk a distance to the next class. The next lesson started already when I got there ... so when I walked into the classroom the sir grabbed me at my chest and pulled me a few times and shouted at me that I am always late for his class ... But when other children come late he allows them in and doesn't even say anything to them".

Upon being asked to explain how he responded to the treatment discussed above, Gary said the following:

"Well, it made me extremely mad. I didn't like it and I walked straight to my seat, but after a few minutes I got up and just walked out of class ... I was just too angry. I wanted to go to the principal's office to tell him what this teacher did to me, but then I thought maybe he won't believe me. I then went to the toilet and waited there for the next period to start. That afternoon as I was walking home, I passed a few guys whom I know because they are known gangsters in our area and they live in the flats near our house ... I really felt like telling them about what happened to me in school, because I know they would have done something to that sir at school. But then I thought again if they do that they will expect me to join them ... and for that I was not ready".

\section{Discussion}

Overall the evidence of the research suggests that a poor school climate and dysfunctional teacher-learner relations can discourage learners from attending school and certain classes and lead to truancy. Moreover, it is clearly demonstrated by this study that truancy levels seem higher where there are less supportive relations between teachers and learners and more disruption of learning time through learner misbehaviour. Thus, comparatively speaking, learners who feel alienated or like unwelcome visitors are less likely to attend, while another group has a sense of entitlement and ownership. Furthermore, it seems that truants in the research area often perceive their socio-economic class status and home environment as the basis on which teachers developed a low expectation of their academic abilities. This not only appears to encourage truancy prone learners to feel marginalised, but in the end could also result in them giving up on 
school completely. Accordingly, school it seems becomes less meaningful and perceived as a place for advantaged and so-called 'bright' learners only.

Many teachers, even those with the greatest intentions, appears to have a tendency to blame learners' undesirable school behaviours and poor scholastic performance on their parents, without taking into consideration that their very own uncaring behaviour poor attitudes, unkind classroom behaviour and outdated approaches to teaching and learning may even play a more significant role in leading learners to truant and eventually drop out. Based on the current research findings, it seems that truancy can be seen as a response to a setting that is perceived as marginalising and potentially hostile. Thus, learners were more likely to truant if they viewed the school's discipline policy as unfair and found it difficult to engage with their teachers

Gauging by the high level of unhappiness and sheer frustration expressed by Gary, the truant learner in the case study, school related factors like poor teacher-learner relationships, boredom, discriminatory conduct by teachers and poor teacher role modelling seem largely responsible for causing truancy. What are complicating matters further for Gary is the fact that his mother who is a single parent who did not reach high school level herself doesn't demonstrate any true concern and support for him and shows no interest in his scholastic progress. In view of the aforementioned, neglect thus occurs in two of the micro systems of Gary, namely at home and in his learning environment. Based on Bronfenbrenner's ecological system's theory which underpinned this study, it is ideal and conducive for healthy for development and adjustment if all systems are supportive of the individual. However, the fact that learners are often exposed to negative school experiences which may result in truancy and ultimately school dropout go a long way to substantiates the existence of adverse influences on the micro systemic level of these learners.

Somewhat ironically, in view of the current study, truancy also emerged as a response to other forms of student resistance to being ill-treated and marginalised by teachers. Learners who experience rejection by their teachers and do not feel connected to their school are less likely to attend and more likely to be truant. Therefore, to the other extreme, it is not too surprising that in cases where the school climate provides a safe, loving, caring and nurturing environment for all learners, regardless of class, academic ability, race and so forth, truancy is absolutely limited or in many cases a phenomenon that is even unheard of. In the final analyses, being a victim of ill-treatment and ostracism for learners seem to be inextricably linked to non-attendance and truant behaviour among learners which is highly likely to increase the risk of ultimate absolute school disengagement.

\section{Conclusion}

To date there has been no single solution or panacea to resolve truancy, despite much good professional practice and effort. All the evidence suggests that different learners and different schools require their own solutions (Eastman, Gooney, O'Connor \& Small, 2007). Persistent truancy and absence from school have serious negative consequences both for truants themselves and for society, which may include criminality and the likelihood for truants to endure significant problems in their later adult lives.

Nevertheless, the evidence of the current research suggests that interventions with learners who are chronically truant must focus on supporting them to become more engaged through the provision of educational and emotional experiences at school that are safe, caring, academically supportive, interesting and relevant. To this end, much more research is desperately needed as to how and why some schools are able to improve their learners' attendance while others are not. Needless to state, a lot more research into good practice in managing pupils' truancy and non-attendance is required at school and at local department level. Many successful school-based schemes are no reported in the literature. If all current and future truancy search findings particularly those aimed at teacher attitudinal change in delivering their services could be disseminated and implemented, levels of learner truancy and non-attendance hopefully might start to decrease significantly.

\section{References}

Berk, L. (2003). Child development. Boston: Allyn and Bacon.

Davies, J.D. \& Lee, L. (2006). To attend or not to attend? Why some students chose school and others reject it. Supporting for Learning. 21 (4).

Donoghue, J. (2011). Truancy and the Prosecution of Parents: An unfair Burden on Mothers. The modern law review. 74 (2) $216-244$.

Darmody, M., Smyth, E. \& Mc Coy, S. (2008). Acting up or opting out? Truancy in Irish secondary schools. Education review. 60 (4).

De Vos A.S., Strydom, H., Fouche C.B., Delport C.S.L. (2005). Research at Grassroots for the Social Science and Human Services Professions. Van Schaiks: Pretoria.

Eastman, G. Gooney, S.M., O'Connor, C \& Small, S.A (2007). Finding Effective Solutions to Truancy, Research to Practice Series 5, 
Wisconsin II: University of Wisconsin, Madison.

Fallis, R.K. \& Opotow, S. (2003). Are students failing school or are schools failing students? Class cutting in high school. Journal of Social Issues, 59, 103-119.

Gullat, D.E. \& Lemoine, D.A. (1997). The school truancy dilemma. Retrieved May 26, 2014 from http:// www. edrs.com

Hendricks, M. A., Sale, E.W., Evans, C.J., McKinley, L. \& Carter, S.D., (2010). Evaluation of a truancy intervention in four middle schools. Psychology in the Schools, 47 (2).

Henry, K.L. (2007) Who's Skipping School: Characteristics of Truants in the $8^{\text {th }}$ and 10th Grade. Journal of School Health. 77 (1).

Henry, K. L. (2010). Skipping School and using drugs: A brief report. Drugs: education, prevention and policy. 17 (5): 650-657.

Kim, H.Y. \& Page, T. (2013). Emotional bonds with parents, emotional regulation and school related behaviour problems among elementary school truants. Journal of Child and Family Studies. 22: 869-878.

Lindstadt. M. A. (2005). Employing mediation to approach truant. Family Court Review, 43 (2), 303-322.

McCray, E.D.(2006). The persisting issue of truancy. Intervention in School and Clinic. 42 (1), 30-33.

Maynard, B.R., Salas-Wright, C.P., Vaughan, M.G. \& Peters, K.E., (2012) Who are Truant Youth? Examining Distinctive Profiles of Truant Youth Using Latent Profile Analysis. Journal of Youth and Adolescence 41: 1671-1684.

Maynard, B.R., McCrea, K.T., Pigott, T.D. and Kelly, M.S. (2013). Indicated Truancy Intervention for Chronic Truant Students: A Campbell Systematic Review. Research in Social Work Practice. 23 (1) 5-21.

Ovink, S.M. (2011). "This Aint My School!" Criminality, Control and Contradictions in Institutional Responses. Qualitative Sociology 34, 79-99.

Reid, K. (2010). Finding strategic solutions to reduce truancy. Research in Education. Manchester University Press.

Sheppard, A. (2009). School attendance and attainment: poor attenders' perceptions of schoolwork and parental involvement in their education. British Journal of Special Education. 36, (2).

Sheppard, A. (2007). An approach to understanding school attendance difficulties: pupils perceptions of parental behaviour in response to their requests to be absent from school. Emotional and Behavioural Difficulties, 12 (4), 349-363.

Ward, C. (2012). South African street children: A survey and recommendations for service. http://panos.org.uk. journalists/tania-gosh. 